\title{
Using Participatory Action Research to Access Social Work Voices: Acknowledging the Fit
}

\author{
Trish Van Katwyk \& Rachelle Ashcroft \\ Version Pre-print \\ Citation Van Katwyk, T., \& Ashcroft, R. (2016). Using participatory action \\ (published version) research to access social work voices: Acknowledging the fit. Journal of \\ Progressive Human Services, 27(3), 191-204. \\ Publisher's Statement This is the pre-print of an article published by Taylor \& Francis in in \\ the Journal of Progressive Human Services on August 17 2016, the final \\ published version is available online at: \\ https://doi.org/10.1080/10428232.2016.1191242
}

How to cite TSpace items

\begin{abstract}
Always cite the published version, so the author(s) will receive recognition through services that track citation counts, e.g. Scopus. If you need to cite the page number of the author manuscript from TSpace because you cannot access the published version, then cite the TSpace version in addition to the published version using the permanent URI (handle) found on the record page.
\end{abstract}

This article was made openly accessible by $U$ of $T$ Faculty. Please tell us how this access benefits you. Your story matters. 
Original Article

Participatory action research and health social work

\section{Trish Van Katwyk}

(School of Social Work), Renison University College, University of Waterloo, Canada

\section{Rachelle Ashcroft}

(School of Social Work), Renison University College, University of Waterloo, Canada

\section{Corresponding author:}

Trish Van Katwyk, School of Social Work, Renison

University College, University of Waterloo, 240

Westmount Rd, N. Waterloo, ON, Canada N2L 3G4 
Email: pvankatw@uwaterloo.ca

\begin{abstract}
The purpose of this paper is to describe a Participatory Action Research project that was carried out with a national group of social work practitioners and educators about the definition of health. This paper will consider Participatory Action Research as a critical methodology, and then describe the importance of using this research methodology with a group of social workers about their conceptualizations of health. Social work is concerned with the experience of health, and yet its unique way of understanding health is frequently subsumed within work contexts that are dominated by bio-physiological conceptualizations of health. The suggestion put forth in this paper is that the social worker's disciplinarian knowledge thus becomes a subjugated knowledge. The research methodology itself was intentional in clearing space and providing legitimacy to the knowledge of social workers. The participants in the research project demonstrated a conceptualization of health that includes social, subjective, and contextualized experience.
\end{abstract}

\title{
Keywords
}

Participatory action research, health, social work, disciplinarian knowledge 
The aim of this paper is to describe the participatory action research (PAR) that occurred with a group of Canadian social workers in the form of a 'living document' research poster that asked the question: How do you define health? We will consider the significance of PAR as a research methodology that showcases the voices of the people about whom the research is gaining information, thereby shifting the relationships between researcher/researched to a mutual peer-to-peer opportunity for dialogue. We will also look at the significance of PAR in its commitment to creating action with research participants as the research project itself. In this case, the PAR project was the creation of a living document that incorporated the voices and definitions of a wide group of Canadian social workers during a two day joint national conference of the Canadian Association for Social Work Education (CASWE) and the Canadian Association of Social Workers (CASW).

\section{Positivism in Health Research}

Positivism is pervasive among health care workers and researchers, and has an enormous impact on how health continues to be viewed and investigated (Raphael, 2006). Positivism asserts reason, objectivity, and logic as core values guiding research (Crotty, 
1998). The inclusion of diverse and subjective perspectives is considered problematic from a positivist perspective. Dominant health methodologies limit the inclusion of personal interests such as opinions, emotions, intuition, and insights during the research process (Longino \& Murphy, 1995). A strict scientific method intends to uncover meaning considered to be inherent in thobjects that it regards (Crotty, 1998). This results in a privileged and highly specialized knowledge that excludes nonspecialists (Waldram, 2004). Positivist methodologies historically help reify dominant knowledge bases of privileged medical professions who are considered legitimate sources of knowledge (Illich, 2005). For example, epidemiological methods guide research in public health (Baum, McDougall, Smith, 2006). Epidemiological methodology is a medical science that focuses on population health. PAR provides a rich alternative methodology that extends beyond the limited scope of traditional positivist approaches.

\section{PAR as a liberatory approach to health research}

As a methodology, PAR is vastly different than the dominant approach to knowledge production. PAR provides inclusion of critical theoretical considerations that are applied closely to the research project. Ethics and research relationships take on a new 
significance that are absent from positivist driven methods. The conceptualization of a research methodology that could be valid, robust and liberatory has been taken up as an important possibility and a worthy research goal. Individuals and communities who have experienced oppression in their role as participants in research projects are being reconsidered as active allies in the research project (McTaggart, 1991), with an expertise that can only be accessed through non-oppressive research relations. PAR is specifically concerned about the kind of relationships that get built in the process of research. By meaningfully inviting individuals into the research process, as partners who are co-creating the knowledge being explored, PAR intends to shift power dynamics and create egalitarian research relationships. These egalitarian relationships are developed through participation and validation of the subjective experiences of everyone who has become part of the research exploration.

At the same time, the oppressive characteristics of a research methodology that brought about little evident and immediate change for the research subjects were being critically examined (MacDonald, 2012). Questions were being asked about the benefit that the study of population health might have for the immediate experiences of the individuals 
and communities being researched (Baum, McDougall, \& Smith, 2006). The critical considerations of research began to exhort the necessity of action or change that could be experienced in the everyday lives of those being researched.

\section{PAR's compatibility with Social Work}

PAR is envisioned as a liberating research methodology, developed out of an ethical and critical concern for the impact of research on oppressed individuals and communities. In the practice of health, we continue to see the privileging and dominance of a medical model whose parameters do not entirely cover the disciplinary ground of Social Work. Such a dominant model can de-stabilize equitable relations among the continuum of health practitioners, can mute the structural considerations of Social work, and can exclude or demote the significant contributions that coalesce to create robust interdisciplinary responses. Heinonen et. al (2009) address this concern as they describe how often Social Work is hosted by medical facilities, where approaches to care focus on short-term interventions and the cessation of symptoms. What gets lost, the authors suggest, is a disciplinarian perspective that can enrich the practice that can occur with individuals. They write, "A holistic view of physical health, mental health and well-being embedded in 
unique social experiences frames our thinking about the practice of social work in physical health and mental health settings. The inter-connections between people's everyday lives and their health are often complex and situated in a particular place and time in a rapidly changing world" (142).

Nathan and Webber (2010) also write about the knowledge and identity of social workers getting marginalized within services that privilege the medical model of understanding. They found this to be a particularly salient concern for mental health social workers. They conducted a qualitative study with a group of mental health social workers and the agencies where they were situated. Their findings suggest that mental health social workers are being absorbed into a psychiatric hegemony, characterized by a biomedical discourse with practice-based texts such as "patients", "diagnosis" and "treatment". The social workers they interviewed felt that they did not have the capacity to present any meaningful challenge to the institutions within which their practice was situated. Nathan and Webber (2010) suggest a renewed focus on what is unique to the social work discipline, as a way to enhance understanding and work with individuals who are seeking the support of a mental health social worker. They recommend a strengthened professional voice in the 
context of dominant biomedical approaches.

Beddoe (2010) similarly has conducted qualitative interviews with social workers, and finds in their descriptions the use of battle metaphors as social workers described their attempts to claim expertise in an interdisciplinary setting. The social workers she interviewed described a disciplinarian hierarchy at their practice settings, with the social work profession located low on the hierarchical ladder. Beddoe (2011) suggests that social workers feel marginalized in their health work environments, with little professional and social value within a field of professional health practice. Sinding (2013) describes a similar struggle for social workers to have their work recognized and valued in a care setting. According to Sinding, much of the work that social workers were doing that was in line with their disciplinarian knowledge went unsanctioned by the institution within which their practice occurred. The social work that Sinding examined occurred with individuals who had been diagnosed with a psychiatric illness, as well as with individuals who had been diagnosed with cancer -- it was in both of these contexts that social workers found their practice significantly undervalued. Much more literature exists that critically explores the impact of a dominant medical model, and the specific impact this has on the social work 
profession (i.e. Beresford, 2005; Morely, 2003; Bleecher, 2009).

\section{Using PAR to investigate Social Work's definition of health}

The aim of this PAR project was to explore with social workers their disciplinarian conceptualization of health. Social workers are very engaged in health work, in a variety of settings and contexts (Heinonen et. al, 2009). In an exploration of the definition of health, we wanted to explore how social workers are themselves defining health. We submitted a research poster to the joint national conference of CASWE and CASW that brings together social work faculty members of Canadian universities, other social work educators, practitioners, researchers, and students. This joint annual conference was held at Brock University in St. Catharine's, Ontario, Canada on May 26-29, 2014. The only information that was on the poster was a brief description of PAR. The rest of the poster was blank, entitled with the question "How do you define health?" There were pens and blank stick-it notes available at the poster. The poster was displayed among the other research posters, for two of the two and a half day conference. All of the posters were displayed in a central location, and conference attendees had numerous opportunities to look at the posters throughout the conference. Conference attendees posted their answers to the question "How 
do you define health?" so that by the end of the two days of display, there were 64 responses posted. The research poster was, thereby, created by the conference attendees who provided responses to the poster question. It was a research poster that was created by the research participants. This was a research project that had received ethical approval by the University of Waterloo Research Ethics Review Board.

Respondents were aware that while there was no identifying information asked for on the stick-it notes, the responses were written and posted in a public area, so complete confidentiality could not be guaranteed. The poster became a living document that continued to develop over the span of the conference to reveal the diverse and multitude ways in which health is understood within the social work profession. The poster became the creation of an evolving community of voices featuring the experience of social workers.

The critical work of PAR is the simultaneous reconsideration of the relationships and the impact of research. PAR is a research methodology that invites individuals and communities to participate in meaningful ways in the research project (Borg, et al, 2012; Kemmis \& McTaggart, 2005). These are the experts whose contributions are crucial to the knowledge that can be gained through research explorations. At the same time, action has 
Van Katwyk and Ashcroft Participatory action research and health social work 0(0)

become an integral aspect of research -- a research project needed to result in action, and both the research and the action requires the full participation and contribution of the communities and individuals most relevant to that being explored (MacDonald, 2012; Fals Borda, 2001).

A living document: Social Work and health

This PAR project emphasizes the voice and experience of social workers in its exploration of the conceptualization of health. Additionally, it entails as action the development of a poster that demonstrates the voice and experience of social work practitioners and educators. This poster exists as a living document, evolving with emerging themes over the duration of this national conference, CASWE-ACFTS 2014. The 64 responses reflected an appreciation for the fluid and subjective experience that is health. To our knowledge, there is limited inclusion of this type of PAR "living document" in conference proceedings. The numbers of responses suggests that this is one way to successful engage a diverse group of social workers. 


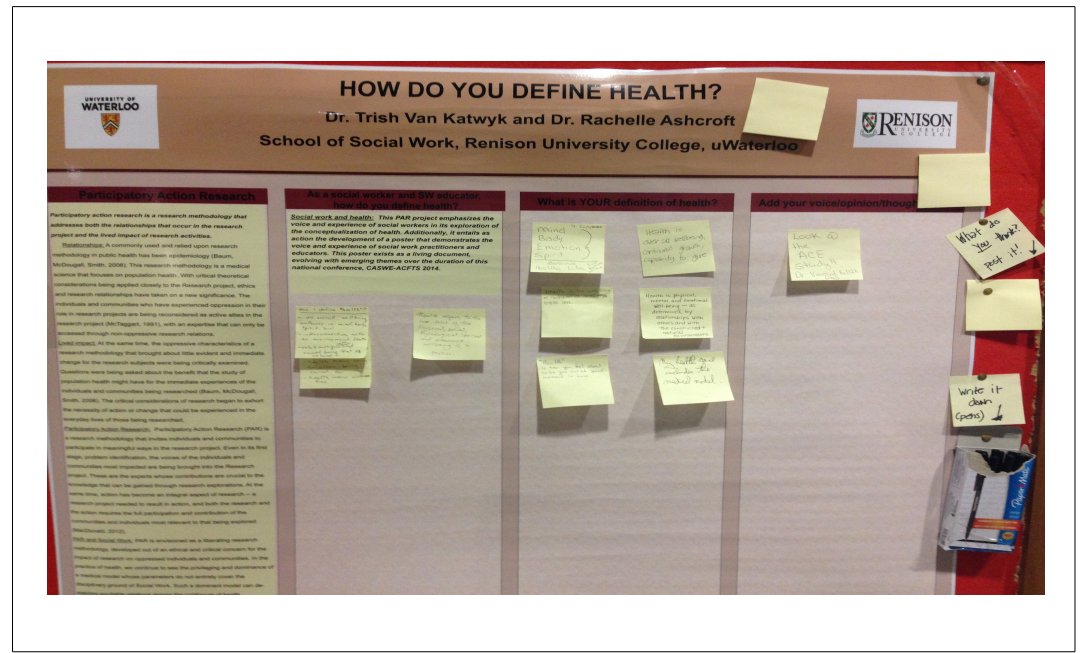

Image 1. photograph of the PAR poster on day 1

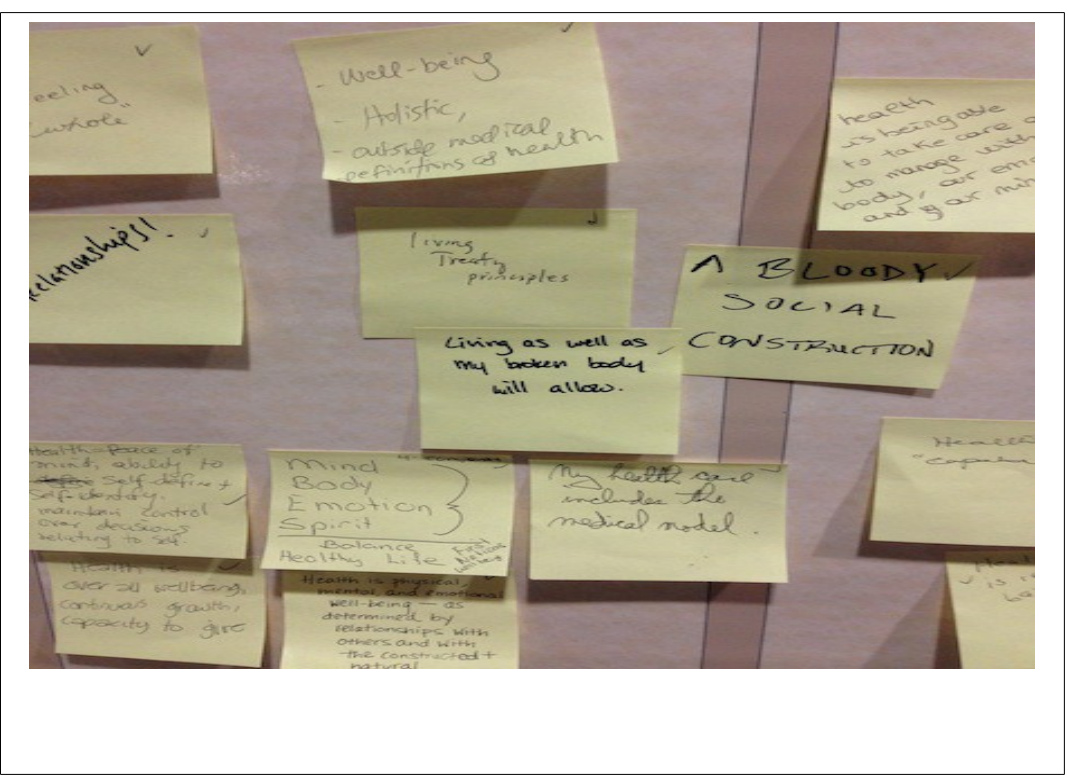

Image 2. A photograph of the PAR poster on day 2 


\section{Generalized findings}

Contributions to the living document demonstrated that social work provides alternative views of health that enriches the broader health discourse (Author \& Author, 2014). Many responses referred to a holistic conceptualization of health, with attention being paid to societal structures, the environment, body-mind connection and context. While the medical model featured in the responses, some resistance to the medical model was specifically noted. Health was also discussed as an empowerment in itself, and as a state of inner peace that brings spirituality into the conceptualization of health. Some social worker respondents insisted on a subjective and fluid understanding about health, while others referenced the connections between health and social justice with assertions of the need for equitable opportunities for health. Ultimately, what the responses portray is an enhanced portrait of health that moves beyond the physiological focus of the medical model. We see then, in the findings, evidence of a disciplinarian voice that is unique and differentiated from the conceptualization of health endorsed by the medical model. Although the scope of this article is not on the actual research findings, they are presented 
elsewhere (Author \& Author, 2014).

What this study supports is the voice of the social work profession and the unique perspectives that social work brings to the examination of and conversation about the definition of health. As an example of the unique perspectives of social work, while exploring the ways in which trauma is conceptualized, Joseph and Murphy (2014) expressed concern that the medically-based psychiatric validation of a Post Traumatic Stress Disorder diagnosis has become the basis of a national approach to practice that has influence on the approaches available to clinical social work. It is their contention that this becomes an individualized conceptualization that fails to incorporate the systemic appreciation that the social work discipline can bring to its considerations of trauma, its impact and its process of recovery. They refer to social work knowledge and identity being intricately bound with a consciousness about systemic and community-based responses.

\section{Discussion}

The purpose of this paper is to intentionally use a specific research methodology, PAR, to explore social workers' definitions of health. PAR explicitly supports the voices of those being researched and endeavours to create research that is at the same time action to 
support the experiences of those individuals who are the focus of the research. In this case, the voices of social workers in the health community were highlighted in order to create a living document that was displayed at a national professional conference. What the research poster presented was a diverse and discipline-relevant definition of health. Such a definition has great value, and can contribute in important ways to the health field, strengthening interdisciplinary teams' work, clarifying the advocacy work that social workers can bring to the health field, and expanding the kinds of relationships and identities that can be developed between service users and social workers. The PAR methodology underscores the value of the voices, knowledge and contributions of social workers in their health work. Social determinants of health

PAR methodology establishes the expertise of research participants. One important contribution that social workers are able to make to the health field is their professional training and expertise about the significance of social determinants when it comes to an experience of health. The social determinants of health is a perspective applied to the conceptualization of healththat has been gaining global support (Marmot, 2005). The social determinants of health, as a conceptualization, make powerful links between health and 
social experience, put succinctly by one of the PAR project's social worker respondents: "Wealth equals health". The consideration of social determinants of health is an appreciation of an intersectionality that weaves together social experiences to further embrace the complexity of social processes and the impact that these processes have on health and healthcare.

The concept of social determinants of health is significantly relevant to social work disciplinarian knowledge, with its allegiance to a consideration of the structural context. The consideration of the social determinants of health can be, then, easily and even enthusiastically absorbed into social work practice. They represent the contributions that the social work profession is able to make to any conversation about health. It is important to consider carefully and critically the way in which the social determinants of health are acknowledged and taken up in local and global health conversations. It is important to consider the ways in which the voice and knowledge of social work retains a position of validity not subsumed by the influence of an already-dominant medical model discourse. This study is, therefore, significant in its participatory inclusion of the social work voice, and in its development of a conversation about health that is centred by social work 
disciplinarian knowledge. We would like to spend some time considering the impact that the dominant medical model can have even on a conceptualization so deeply relevant to the social work lens: the social determinants of health (Author, 2010).

The social determinants of health incorporate a contextual and structural series of considerations into an understanding about health and healthcare. The social determinants of health are a reference to the social resources that are necessary for health, and the social situations that determine the unequal distribution of those resources (Raphael, 2011). They are the "economic and social conditions that influence the health of individuals, communities and jurisdictions as a whole" (Raphael, 2004, p.2). According to the 2010 WHO report Equity, social determinants and public health programmes, "Social Determinants of Health (SDH) are a broad concept encompassing nearly all aspects of life, including distribution of power, income, goods and services and the circumstances people live in such as their access to health care, schools and education; their conditions of work and leisure; their homes, communities, and rural or urban settings; and their chances of leading a flourishing life" (http://whqlibdoc.who.int/publications/2010/9789241563970_eng.pdf). According to the 
Public Health Agency of Canada (PHAC), social determinants of health include socioeconomic status; networks of social support; education; literacy; employment; working conditions; communities and neighbourhoods; personal health practices; coping skills; psychological development; gender and culture (Wolbring, 2011). They also include LGBTQ identity; First Nations, Metis and Inuit identity; ability; and age (Mikkonen and Raphael, 2010) .

The social determinants of health, as a concept, becomes an aspect of the structural awareness that social work brings to the health discourse. Many of the PAR study's participants refer to social and environmental context in their definitions of health. Through out social work literature, we can find examples of the structural and contextual considerations that become part of the unique work that social workers can engage in. For example, the social worker is uniquely positioned to address the complexities inherent in the experience of individuals coming to Canada seeking asylum from their countries of origin. The social experience for the asylum seeker includes many levels of displacement, social isolation, ethnic and racialized experience, language and literacy challenges, dissonance, cultural transition, unemployment, loss, and trauma (Masocha and Simpson, 
2011). The structural perspective of social work is able to accommodate and acknowledge the complexity of such experience, even in work that is focusing on the mental health concerns of the individual seeking asylum. Social work tells us that there is a context, and that there are multiple dimensions to an experience. Social work links together the many dimensions of personal identity, and insists that these dimensions are equally significant, requiring balance and harmony between them. Some of the PAR study respondents referred to a holism that would include multiple dimensions of self, environment and experience. Masocha and Simpson (2011) recommend a model of mental health social work practice based on such an appreciation of the many dimensions of personal experience: "The interface between [mental health concerns] and class, poverty, poor social capital, unemployment and poor housing should also be given due consideration in any plausible explanation of the high incidence of mental illness within the migrant populations" (pp 431). Another study related to social work with individuals seeking asylum in Canada frames a holistic exploration in a social justice lens (LaCroix, 2006). LaCroix (2006) details the broader considerations that need to be brought into social work with individuals who are seeking asylum, identifying the need to understand the international context and to 
understand the Canadian procedures and policies that the person seeking asylum is needing to negotiate. She suggests that it is when we can gain this broader context that we can most adequately understand the oppressions that people have and are being exposed to. For example, we can look at current policy and see that it impedes the refugee's access to full employment, and how individual's professional achievements are nullified. The refugee/immigration policies also have secondary outcomes such as family separation which can contribute to an experience of further marginalization, leading potentially to psychological trauma, depression, family break down, social isolation, and financial hardship (LaCroix, 2006). As social workers, we know that these experiences circle back, creating the conditions for deep and chronic difficulties.

The comments of the PAR study's social work respondents reflect diversity in what the various dimensions of personal experience are, from an interpersonal set of dimensions such as body, mind and spirit, to a contextualized set of dimensions including the planet and even previous and forthcoming generations of people. Social work disciplinarian knowledge acknowledges the importance of holistic and structural considerations of health. We know, as social workers, that context, structure and holism cannot be demoted or 
oppressed by the medical model for understanding health. Indeed, our awareness supports an understanding of physiological experience as being one of, and not the only one of the dimensions related to the experience of health. The social determinants of health are a series of social experiences, whose consideration enhances the elements in the definition of health (social, economic, spiritual, etc.) and also are complex and intricately linked, so that a discussion about poverty without a consideration of race, gender, ability and LGBTQ identity, for example, becomes inadequate (Ou Jin Lee and Brotman, 2013).

One way in which social determinants of health can become situated within the lens of the medical model is in its potentially linear conceptualization. When a social determinant of health such as poverty or racism is understood to be most significant because of its impact on the immune system, we find ourselves, once again, moving to a place of immersion in the medical model view of health. The linear character of such a discourse supports the medical exploration of what agent creates which disease. The focus on a linear relationship between social experience and physiological disease adds additional strength to the medical viewpoint. The dominance of such a viewpoint discounts then the complex and fluid relationship that the social work disciplinarian voice claims to exist 
between social and subjective experience. The dominance of such a viewpoint also discounts that many dimensions of health that we know, as social workers, to exist, where the physiological state is important, as is the spiritual, social, cognitive, relational, economic, environmental, historical and future state.

\section{Meaningful interdisciplinarian Social Work presence}

The voice of the social worker can easily be lost or de-valued in the health field, overshadowed by the bio-medical lens. The significance of PAR methodology in this case is the manner in which it showcased the voice of the social worker, by collaboratively creating a research poster about how social workers define health. These voices represent the important contributions that social workers can make to the dialogues about health support that occur on the interdisciplinary team. It is important to understand health in a discipline-specific manner. The manner in which health gets defined becomes profoundly relevant to the very identity of the social worker. That identity can be an important and unique contribution to the interdisciplinary team. Payne (2006) describes how post-modern understandings about identity acknowledge the ways in which identities develop in interchange. He describes the interdisciplinary team as a significant place where 
professional identity can occur, as it is a place of multi-professional interaction. He goes further to describe the important contributions that social workers have to make to the understanding of individuals' experiences, and, thus, how critical is the social worker's professional interactions and identity on the interdisciplinary teams. Morley (2003) also describes interdisciplinary teams, but expresses concern about what occurs for the social work identity when the bio-medical model is privileged in the team exchanges. The social work identity is muted, indeed, to the point of serving only a supporting role to the medical model, so that the tasks and roles of the social worker are defined by the medical model rather than a focus and knowledge that is unique to the social worker identity. The interdisciplinarian response is enhanced when the social worker lens can be added in a meaningful way to the considerations being made and the responses being developed.

\section{Person-centred practice and advocacy}

By showcasing the knowledge of social workers, this PAR project begins to demonstrate a portrait of the advocacy that occurs with discipline-specific responses to health support. PAR methodology, as an action and as a liberating response, has, in this case, created a space for the representation of a professional relationship and its 
possibilities to be displayed. The project shows how a social worker lens impacts the relationships that can occur between service provider and service user. Just as the social worker is able to contribute an alternative and enhanced set of considerations to the interdisciplinary team by connecting with aspects of the person beyond their biophysiological state, so too can the relationship extend beyond bio-physiological experience. The social worker places the person that they are working with at the very centre of the relationship, so that many aspects of who that person is become profoundly pertinent to the relationship and to the change efforts that have become the work that is happening with that person. Heinonen, Metteri, \& Leach (2009) refer to the unique perspective that social workers bring to service consideration, contributing a holistic appreciation that enhances service response. Paying particular attention to mental health practice, Farone (2006) found that social work, with its ecological perspective, is well suited to address the complexities pertinent to service provision.

In a study of a large and representative mental health centre, Bleecher (2009) explored concerns about the supports that are available to individuals who have been diagnosed with schizophrenia and are connected with mental health services. Bleecher 
analyzed the assignments of service users to the interdisciplinary service team members. What she found was that a disproportionate number of individuals diagnosed with schizophrenia were assigned to work with nurses. In fact, the assignment numbers were so disproportionate that nurses were left with unwieldy caseloads. Schizophrenia was a diagnosis that became absorbed by a bio-medical understanding of mental health, and the only services available to the service users with such a diagnosis were connected to the medicalization of the individual's experience. The individual becomes their diagnosis, and the multiple dimensions of experience are lost. Social workers did not have the opportunity to respond to systemic and holistic aspects of the individual, and nurses did not have the time to do more than attend to the medical concerns of the individual, such as the dispensing of medication.

Social workers, with their specific knowledge, are able to see many other aspects of an individual's life, and are able to understand the diagnosis of schizophrenia in a nuanced way, so that the structural aspects of a person's experience and the structural impact of a psychiatric diagnosis can be responded to. Indeed, Bleecher (2009) asserts that schizophrenia is one of the most serious of psychiatric diagnoses, and the individuals who 
received such a diagnosis are significantly vulnerable, a vulnerability that social workers are trained to respond to with advocacy and holistic support. Social workers, she suggests, are ideally positioned to coordinate the care and guarantee the equity and quality of such care because they are trained to think in systemic terms. She writes about the unique advocacy capacity of social workers: "They also have the commitment and skills to work with people with psychological, social, and mental health challenges and to intervene in stigmatizing and disabling processes in the care system (factors typically ignored in the literature on integrating mental and physical health care)" (15).

Nathan and Webber (2010) also talk about the advocacy role that social workers carry when the whole person is placed at the centre of service provision. They acknowledge the dominance of the medical model, and the experiences of the social worker who is working within any health-related service. While social workers can become the instruments of such a powerful model of understanding and response, they also are incomparably positioned to advocate for the service user who is a part of the dominating institutions of which they are a part. The capacity to advocate comes from social work's core defining principles related to justice, equity, and self-determinism. These principles 
distinguish social work as a profession.

\section{Intersubjective relationships}

By showcasing the voices of its social worker participants, this PAR project attends to the very identity of the social worker, and the ways in which that identity gets positioned in its various relationships. The identity of who the social worker can be in those relationships becomes an unavoidable consideration. In other words, when a holistic, structural and subjective world view is able to guide a relationship, critical reflexivity becomes a necessary social work stance, and conscious, even intentional, participation in relationship can occur. The relationship, then, becomes an experience of intersubjectivity, where the identity of each member of the relationship becomes intricately linked to the identities of the other members of that relationship. When relationships are conducted in such a way where the impact of each participant is deeply acknowledged, it becomes possible for people to become transformed by their relationships, including the social worker who has been a part of those relationships. This becomes the potential of a discipline where the uniqueness of its definitions are able then to guide the identities that can occur within that discipline. 
O'Leary, Tsui and Ruch (2013) have examined the influence of the medical model on the relationship development that occurs in the social work profession. The medical model relationship, they describe, is built upon principles of hierarchy and expertise, with the doctor at the center of the power structure. This necessitates strong boundaries between the service user and the service provider, a separation between the social worker and the person using their services.

The medical model has been heavily criticized in social work literature, because of the way in which it has influenced the kinds of relationships that can occur between the social worker and the service user (i.e. Beresford, 2005; Morely, 2003; O'Leary et. al, 2013; Tower, 1994; Warsaw, 1989). O'Leary et al. (2013) have looked specifically at the possibilities that exist for the relationship, if social work knowledge gained more value. Similarly, Ruch (2005), discusses the evolution of social work that has made way for a post-structuralist appreciation of complexity and diversity of relationships with people who have experienced oppression and marginalization. Healy (2005) also cites the poststructural and critical theoretical impact on social work, so that the professional relationships are being critically appraised for their transparency and anti-oppressive 
potential. Contemporary approaches to social work, such as narrative theoretical practice, forefront collaboration, and identify the boundaries proposed by the traditional approach to health work as being disempowering to the service user (Bird, 2000). Post-structural considerations have inspired a reconsideration of the power dynamics that are present in social work relations, and cast a critical eye on the relationships that support the expert social worker at the centre of the intervention, as has been constructed by the influence of the medical model. When social work is able to side step the influence of this model, alternative relationships become possible, where the diversity of lived experience can become a foundational characteristic of each unique relationship. The mutuality of the relational exchange can also be acknowledged, which brings together social worker and service user in the creation of a truth that has the potential to transform. The voice of the service user is recognized as being strong and valid, while the presence of the social worker in the relationship is appreciated as significant and potentially flawed (O'Leary et. al, 2013).

Miehls and Moffat (2000) have explored the importance of the social worker as an individual who is willing to place her/himself in the relationship, which would require that 
the social worker be open to the personal change that would be the outcome of such an approach to relationships. Of this reflexive self-location, they write, "It's not about having the right gaze on to the Other, it's about intersubjective involvement with the other, in order to be fully facilitative of the potential of difference and relationship between differences" (Miehls \& Moffatt, 2000). This creates a relationship that is multi-dimensional, non-linear, and profoundly transformational. It embraces the acknowledgement that social workers are as much a product of the larger structures as their service users are, subject to the power relations that define race, class, gender, and numerous other social experiences that can obscure the experience of health (Veenstra, 2011). With critical reflexivity, social workers can enter into their relationships with an awareness of their potential to re-enact the oppressions that characterize the power relations. They are able to remain open to the holistic and systemic experience of the service user, and the encounter can become an intersubjective reciprocity, so that transformation is able to occur at micro and macro levels of experience (Miehls and Moffatt, 2000).

\section{Conclusion}

The purpose of this study was to create a participatory action opportunity for social 
workers to bring their disciplinary identities to a definition of health. Due to the dominance of the bio-medical model, the definitions of health and the organization of practice diffuses the worth and value of contributions social workers are able to make to their health-related work. PAR showcases marginalized voices and creates action. This study showcased the unique voices of social workers and created a research poster that highlighted the distinct ways in which health gets defined by social workers. The responses by social workers presented an understanding of health that is diversified, holistic, and structural. Such definitions do not replace the bio-medical understanding about health, rather they enhance and deepen such understandings. Such definitions find legitimacy in an acknowledgement of social determinants of health. Such definitions also contribute to a solid professional social worker identity within the interdisciplinary team, create a specific advocacy role for the social worker, and contribute to the development of a relational capacity that promises intersubjective transformation and critically reflexive social work practice. 


\section{References}

Author (2010)

Author and Author (2014)

Baum, F, MacDougall, C and Smith, D (2006) Participatory action research. Journal of Epidemological Community Health 60: 854-857.

Beddoe, L (2010) Surveillance or reflection: Professional supervision in 'the risk society'. British Journal of Social Work 40(4): 1279-1296.

Beddoe, L (2011) Health social work: Professional identity and knowledge. Qualitative Social Work 12(1): 24-40.

Beresford, P (2005) 'Service User': Regressive or liberatory terminology? Current Issues, Disability \& Society 20 (4): 469-477.

Bird, J (2000) The Heart's Narrative: Therapy and Navigating Life's Contradictions. Auckland: Edge City Press.

Bleecher, B (2009) The medical model, mental health practitioners, and individuals with schizophrenia and their families. Journal of Social Work Practice 23(1): 9 - 20.

Borg, M, Karlsson, B, Kim, H, and McCormack, B (2012) Opening up for many voices in knowledge construction. Forum: Qualitative Social Research 1 (1).

Crotty, M (1998) The foundations of social research: Meaning and perspective in the research process. Thousand Oaks: Sage.

Fals Borda, O (2001) Participatory (Action) Research in Social Theory: Origins and challenges. In: Bradbury H and Reason P (eds) Handbook of Action Research: 
Participative Inquiry and Practice. London: Sage Publications, pp. 27-37

Farone, DW (2006) Schizophrenia, community integration and recovery implications for social work practice. Social Work in Mental Health 4(4): 21 - 36.

Healy, P (2005) Social Work Theories in Context: Creating Frameworks for Practice. Basingstoke: Palgrave Macmillan.

Heinonen, T, Metteri, A and Leach, J (2009) Applying health determinants and dimensions in social work practice. European Journal of Social Work 12 (2): 139 - 153.

Illich, I. (2005) Disabling professions. In: I. Illich (ed) Disabling professions. London, UK: Marion Boyars Publishers, pp. 11-41.

Joseph, S and Murphy, D (2014) Trauma: A unifying concept for social work. British Journal of Social Work, 44: 1094-1109.

Kemmis, S and McTaggart, R (2005) Chapter 23: Participatory action research:

Communicative action and the public sphere. In: N. Denzin and Y. Lincoln, (eds) The Sage handbook of qualitative research, $3^{\text {rd }}$ edition. CA: Sage Publications, Inc. pp 559-603.

Lacroix, M (2006) Social work with asylum seekers in Canada. International Social Work 49 (1): 19-28.

MacDonald, C (2012) Understanding participatory action research: A Qualitative research methodology option. Canadian Journal of Action Research 13(2): 34-50.

Marmot, M (2005) Social determinants of health inequalities. Lancet 365(9464): 1099-1104

Masocha, S and Simpson, MK (2011) Developing mental health social work for asylum seekers: A proposed model for practice. Journal of social work 12(4): 423 - 443. 
McTaggart, R (1991) Principles for Participatory Action Research. Adult Education Quarterly 41(3): 168-187.

Miehls, D and Moffatt, K (2000) Constructing social work identity based on the reflexive self. British Association of Social Workers 30: 339-348.

Mikkonen, J and Raphael, D (2010) Social determinants of Health, The Canadian Facts. Toronto: University School of Health Policy and Management. Retrieved from: http://www.thecanadianfacts.org/

Morely, C. (2003) Towards critical social work practice in mental health: a review. Journal of progressive human services 14 (1): 61-84.

Nathan, J and Webber, M (2010) Mental health social work and the bureau-medicalisation of mental health care: Identity in a changing world. Journal of Social Work Practice 24(1):15 - 28 .

O'Leary, P, Tsui, MS and Ruch, G (2013) Boundaries of the social work relationship revisited: Towards a connected, inclusive and dynamic conceptualisation. British Journal of Social Work 43: 135-153.

Ou Jin Lee, E and Brotman, S (2013) Structural intersectionality and anti-oppressive practice with LGBTQ refugees in Canada. Canadian Social Work Review 30(2): 157 183.

Payne M (2006) Identity politics in multiprofessional teams: Palliative care social work. Journal of Social Work 6(2): 137-150.

Raphael, D (ed) (2004) Social Determinants of Health: Canadian Perspectives. Toronto: Canadian Scholars' Press. 
Raphael, D (2006) Social determinants of health: An overview of concepts and issues. In: Raphael, D, Bryant, T and Rioux, M (eds.) Staying alive: Critical perspectives on health, illness, and health care. Toronto: Canadian Scholars' Press, pp 115-138.

Raphael, D (2011) A discourse analysis of the social determinants of health. Critical Public Health 21(2): 221-236.

Ruch. G (2005) Relationship-based practice and reflective practice: Holistic approaches to contemporary child care social work. Child and Family Social Work 10: 111-23.

Sinding, C (2013) Stigmas and silos: Social Workers' accounts of care for people with serious mental illness and cancer. Social Work in Mental Health 11: 288 - 309.

Various people. Equity, social determinants and public health programmes. Geneva, Switzerland: World Health Organization, 2010. Retrieved from:

http://whqlibdoc.who.int/publications/2010/9789241563970_eng.pdf

Veenstra, G (2011) Mismatched racial identities, colourism, and health in Toronto and Vancouver. Social Science \& Medicine 73: 1152 - 1162.

Waldram, J (2004) Revenge of the windigo: The construction of the mind and mental health of North American aboriginal peoples. Toronto: University of Toronto Press.

Wolbring, G (2011) People with disabilities and social determinants of health discourses. Canadian Journal of Public Health 102(4): 317-19. 